\title{
DIVERGÊNCIA GENÉTICA EM GENÓTIPOS DE GIRASSOL
}

\author{
Genetic divergence in sunflower genotypes
}

\author{
Edson Perito Amorim¹, Nilza Patrícia Ramos², Maria Regina Gonçalves Ungaro \\ Tammy Aparecida Manabe Kiihl ${ }^{4}$
}

\section{RESUMO}

Uma investigação sobre a diversidade genética entre 15 genótipos de girassol, por meio de 12 características agronômicas, foi implementada no Instituto Agronômico, Campinas, Brasil. Análises de variância univariada e multivariada revelaram diferenças entre os genótipos. A distância generalizada de Mahalanobis indicou um alto grau de divergência genética. Os genótipos foram agrupados em três grupos. As características início do florescimento, $50 \%$ do florescimento, número de folhas e altura da inserção do capítulo contribuíram com grande parte da divergência genética observada. Por meio desses resultados, é possível identificar materiais divergentes e com características agronômicas complementares para o desenvolvimento de novos cultivares superiores.

Termos para indexação: Variabilidade Genética, D² Análises, Melhoramento de Plantas, Helianthus annuus L.

\section{ABSTRACT}

An investigation about the genetical diversity among fifteen sunflower genotypes using twelve agronomical characteristics was implanted at the Agronomic Institute, Campinas Brazil. Univariate and multivariate analyses of variance revealed the presence of differences among the genotypes. The generalized distance of Mahalanobis indicated the presence of genetic diversity. The genotypes were grouped into tree clusters. Among the investigated characteristics, the beginning of flowering, 50\% flowering, leaf number and head height of chapter insertion exhibited high contribution towards genetic divergence. Through these studies it is possible to identify divergent material with further agronomical features for the development of new superior sunflower cultivars.

Index terms: Genetic Variability, D² Analysis, Plant Breeding, Helianthus annuus L.

\section{(Recebido em 23 de outubro de 2006 e aprovado em 9 de maio de 2007)}

\section{INTRODUÇÃO}

O girassol apresenta-se como uma cultura promissora no Brasil, por causa de sua ampla adaptação e excelente qualidade do óleo. Além disso, está inserido no programa nacional de produção e uso de biodiesel (UNGARO, 2006). No entanto, há a necessidade de adequá-lo aos diferentes sistemas de produção das principais culturas de grãos do Brasil, sendo necessários esforços dos programas de melhoramento genético para o desenvolvimento de genótipos que apresentem, concomitantemente, alto teor de óleo, ciclo precoce, porte reduzido, resistência a fatores bióticos e abióticos, além de alto potencial produtivo (OLIVEIRA et al., 2005).

Para alcançar os objetivos citados é imprescindível a existência de variabilidade genética, no germoplasma, disponível para o melhoramento. A partir dessa variabilidade, é possível implementar a seleção para as mais variadas características, buscando o desenvolvimento de linhagens para a formação de híbridos ou a obtenção de variedades de polinização aberta.

A quantificação da diversidade genética pode ser realizada por meio de caracteres agronômicos, morfológicos e moleculares entre outros. No caso de variáveis quantitativas essa variabilidade pode ser acessada utilizando-se medidas de dissimilaridade, destacando-se, entre elas: a distância Euclidiana e a distância generalizada de Mahalanobis. Essa última leva em consideração as variâncias e covariâncias residuais existentes entre as características mensuradas, quando o experimento se encontra sob delineamento experimental (CRUZ \& CARNEIRO, 2003).

Em girassol, a estimativa da divergência genética entre diferentes genótipos vem sendo estudada, visando à seleção de genitores para formação de híbridos ou mesmo a formação de novas populações segregantes, oriundas do intercruzamento de genótipos divergentes com características agronômicas complementares (MANJULA

\footnotetext{
'Engenheiro Agrônomo, Doutor, Pesquisador A - Embrapa Mandioca e Fruticultura Tropical/CNPMF - Rua Embrapa, s/no - Cx. P. 007 - $44380-000$ - Cruz das Almas, BA - edson@cnpmf.embrapa.br

${ }^{2}$ Engenheira Agrônoma, Doutora, Pesquisadora A - Embrapa Meio Ambiente/CNPMA - Rodovia SP 340, Km 127,5 - Cx. P. 69 - 13820-000 - Jaguariúna, SP _ npramos@cnpma.embrapa.br

${ }^{3}$ Engenheira Agrônoma, Doutora, Pesquisadora VI - Centro de Análise e Pesquisa Tecnológica do Agronegócio de Grãos e Fibras/CEGRAFI Instituto Agronômico/IAC - Avenida Theodureto de Almeida Camargo, 1500 - Cx. P. 28 - 13075-730 - Campinas, SP - ungaro@iac.sp.gov.br ${ }^{4}$ Engenheira Agrônoma, Doutora, Pesquisadora I-Centro de Análise e Pesquisa Tecnológica do Agronegócio de Grãos e Fibras/CEGRAFI - Instituto Agronômico/IAC - Avenida Theodureto de Almeida Camargo, 1500 - Cx. P. 28 - 13075-730 - Campinas, SP - tammy@aptaregional.sp.gov.br
} 
et al., 2001; MILJANOVIC et al., 2000; RAO et al., 2004; SUBRAHMANYAN et al., 2003).

Objetivou-se no presente trabalho quantificar a variabilidade genética disponível em diferentes programas de melhoramento genético do girassol e identificar quais características agronômicas contribuem significativamente para essa variabilidade.

\section{MATERIALE MÉTODOS}

O experimento foi instalado no Centro Experimental Central, do Instituto Agronômico, localizado no município de Campinas, Estado de São Paulo. Foram avaliados 15 genótipos de girassol pertencentes a diferentes programas de melhoramento genético (Tabela 1). Cada genótipo foi semeado em uma parcela de 4 linhas de $6,0 \mathrm{~m}$ de comprimento, espaçadas de $0,8 \mathrm{~m}$ entre-linhas e $0,3 \mathrm{~m}$ entre plantas. Somente as duas linhas centrais foram consideradas como parcelas úteis para as avaliações. Foram realizados os tratos culturais exigidos para a cultura, onde se inclui a adubação seguindo recomendação de Quaggio \& Ungaro (1997)

O delineamento estatístico utilizado foi o de blocos casualizados com quatro repetições e as seguintes características agronômicas foram mensuradas:

1. início do florescimento (IF, em dias): anotado no momento em que a primeira planta se encontrava no estádio fenológico R4 (CONNOR \& HALL, 1997);
2. $50 \%$ do florescimento ( $\mathrm{F}$, em dias): anotado quando $50 \%$ das plantas da parcela útil encontravam-se no estádio fenológico R4;

3. número de folhas (NF): observado em cinco plantas competitivas, quando $50 \%$ das plantas da parcela útil encontravam-se no estádio fenológico R4;

4. altura da planta (AP,em $\mathrm{cm})$ : medida da base do solo até a inserção do capítulo, em cinco plantas competitivas da parcela útil;

5. altura da inserção do capítulo $(\mathrm{AC}, \mathrm{em} \mathrm{cm})$ : medida a partir do solo até o ponto central do capítulo em cinco plantas competitivas da parcela útil;

6. diâmetro da haste (DH, em mm): medido a $10 \mathrm{~cm}$ do solo, em cinco plantas competitivas da parcela útil, utilizando-se paquímetro digital;

7. diâmetro do capítulo (DC, em cm): média de cinco capítulos de cada parcela útil;

8. curvatura do capítulo (CC): avaliação visual, realizada por dois avaliadores utilizando a escala de classificação proposta por Knowles (1978);

9. porcentagem de grãos normais $(\mathrm{GN})$ : obtida a partir da contagem do número de grãos normais e chochos de cinco capítulos de cada parcela útil;

10. peso de 1000 grãos (PG, em g): obtido pela razão entre o peso do total de grãos de cada um dos cinco capítulos de cada parcela útil pelo número total de grãos, sendo posteriormente corrigido para 1000 grãos;

Tabela 1 - Genótipos de girassol identificados quanto ao tipo, empresa obtentora e país de origem (IAC, Campinas-SP, 2006).

\begin{tabular}{cccc}
\hline Genótipo & Tipo & Empresa & País \\
\hline ACA861 & Híbrido simples & Advanta & Argentina \\
AGROBEL960 & Híbrido triplo & La Tijereta & Argentina \\
BRSG03 & Variedade & Embrapa & Brasil \\
BRSG08 & Híbrido simples & Embrapa & Brasil \\
BRSG09 & Híbrido simples & Embrapa & Brasil \\
BRSG10 & Híbrido simples & Embrapa & Brasil \\
BRSG11 & Híbrido simples & Embrapa & Brasil \\
CATISSOL & Variedade & CATI & Brasil \\
EMBRAPA122 & Variedade & Embrapa & Brasil \\
EXP1447 & Híbrido simples & La Tijereta & Argentina \\
IAC-Iarama & Variedade & IAC & Brasil \\
M734 & Híbrido simples & Dow Agrosciences & Argentina \\
V20038 & Híbrido simples & Advanta & Argentina \\
V20044 & Híbrido simples & Advanta & Argentina \\
VDH487 & Híbrido simples & Advanta & Argentina \\
\hline
\end{tabular}


11. peso hectolítrico $\left(\mathrm{PH}, \mathrm{em} \mathrm{kg} 100 \mathrm{~L}^{-1}\right)$ : seguindo metodologia recomendada por Brasil (1992);

12. rendimento de grãos por planta (RGP, em g planta $^{-1}$ ): média de cinco capítulos de cada parcela útil, corrigidos para $11 \%$ de umidade.

Os dados foram submetidos à análise de variância e as médias comparadas pelo teste de Scott \& Knott (1974), a 5\%. Foram estimadas as distâncias generalizadas de Mahalanobis, entre os 15 genótipos de girassol, considerando-se as 12 características agronômicas. Utilizou-se também, o critério de Singh (1981) para quantificar a contribuição relativa desses caracteres para a divergência genética.

Tanto a análise de variância quanto as estimativas das distâncias generalizadas de Mahalanobis foram realizadas utilizando-se o aplicativo estatísticocomputacional Genes (CRUZ, 1997).

\section{RESULTADOS E DISCUSSÃO}

Pela análise de variância (Tabela 2) constatou-se que houve diferenças significativas entre as médias dos genótipos de girassol em todas as características avaliadas. $\mathrm{O}$ coeficiente de variação oscilou de 2,76 a $25,84 \%$ para $\mathrm{F}$ e RGP, respectivamente. O valor mais elevado para RGP justifica-se, pois esse é um caráter com herança quantitativa e altamente influenciado pelo ambiente, corroborando com valores encontrados por Hassan (2001).

Em relação às outras características, observou-se a formação de dois grandes grupos, de acordo com o teste de Scott \& Knott (1974). Para RGP, a média ficou em 14,50 g, variando entre 11,62 g e 19,82 g para os híbridos simples V20038 e V20044, respectivamente. Essa média está próxima da observada por Hassan (2001) de 18,7 g planta ${ }^{-1}$ para essa característica. As médias para IF, F, NF, AP, DH, DC e PG estão dentro do intervalo apresentado por Castro \& Farias (2005). Para CC a média foi de 3,71, semelhante à média 3,91 observada em ensaios de girassol conduzidos na mesma região (EMBRAPA, 1997).

O peso hectolítrico teve média de $38,76 \mathrm{~kg} 100 \mathrm{~L}^{-1}$, estando dentro da faixa observada por Carter (1978) que foi de 36,40 até 41,60 kg 100L ${ }^{-1}$. Já a porcentagem de grãos normais teve média de $75 \%$, podendo ser considerado alto em função do déficit hídrico ocorrido durante a condução do ensaio.

A precipitação acumulada entre março e julho de 2006 foi de 290 mm, enquanto a série histórica (1961-1990) indica valores em torno de $370 \mathrm{~mm}$ para o mesmo período (EMBRAPA, 2006). Gomes (2005) encontrou maior demanda hídrica no período de formação do botão floral, época em que a precipitação foi nula, o que diminuiu o diâmetro de capítulo, o número e o peso de sementes. Cabe destacar que, durante o período de enchimento de grãos (maio-junho), a precipitação acumulada não ultrapassou $60 \mathrm{~mm}$, o que também contribuiu para redução no RGP (SINGH \& SINGH, 2000).

A distância generalizada de Mahalanobis permitiu separar os genótipos em três grandes grupos. No grupo I estão incluídos oito genótipos, no grupo II seis genótipos e no grupo III apenas um genótipo (Tabela 3). No grupo I foram incluídos os genótipos pertencentes aos programas de melhoramento brasileiros (IAC, Embrapa e CATI) enquanto que no grupo II somente os pertencentes aos programas argentinos (Advanta, La Tijereta e Dow Agrosciences). O grupo III foi constituído somente pelo híbrido simples Agrobel 960, de origem Argentina.

A comparação das médias, para as doze características sobre estudo e os grupos obtidos por meio da distância de Mahalanobis, permitem inferir sobre diferenças entre os três grupos (Tabelas 2 e 3). No grupo I, estão presentes genótipos com intervalos entre a semeadura e o início do florescimento (IF) e 50\% florescimento $(\mathrm{F})$ menores, classificados como precoces, enquanto que no grupo II estão inclusos apenas genótipos mais tardios, em relação ao IF e F.

De acordo com Oliveira et al. (2005) os programas brasileiros buscam selecionar genótipos precoces, visando aproveitar a entresafra das grandes culturas, fato ainda pouco explorado na Argentina, onde o girassol é cultivado como cultura principal e seu ciclo varia de médio a tardio (ROMANO \& VÁZQUEZ, 2003). A seleção nesses dois ambientes distintos pode ter contribuído para a separação, em diferentes grupos, dos genótipos pertencentes aos programas de melhoramento brasileiros e argentinos. Resultados semelhantes foram encontrados por Sankarapandian et al. (1996), Subrahmanyam et al. (2003) e Teklewold et al. (2000), avaliando a divergência genética entre germoplasmas de girassol de origens diversas.

A maior distância genética foi observada entre os genótipos BRSG03 e V20044 $(280,32)$ e a menor entres as variedades Catissol e Embrapa 122 (6,70). A distância média entre todos os possíveis pares de genótipos foi de 80,15 (Figura 1).

A análise para estimar a contribuição relativa de cada característica para a expressão da divergência genética indicou que os caracteres IF $(13,10 \%), \mathrm{F}(37,10 \%)$, AC $(18,55 \%)$ e o NF $(9,10 \%)$, foram os que mais contribuíram para a divergência total entre os 15 genótipos de girassol $(78,05 \%)$ (Tabela 4). Alvarez et al. (1996) verificaram que o início do florescimento e o número de folhas também foram 


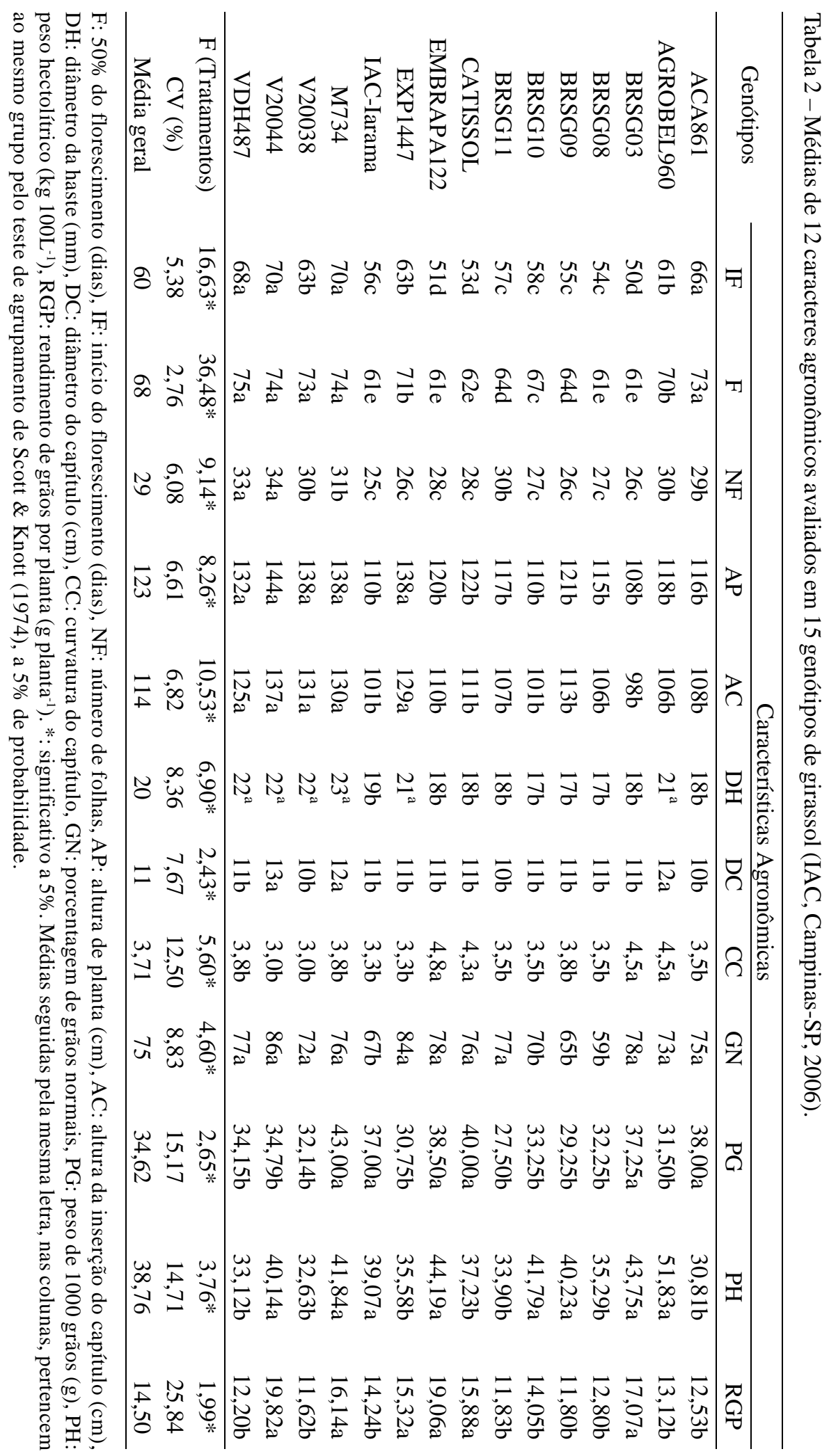


Tabela 3 - Distribuição dos 15 genótipos de girassol, em diferentes grupos baseado na contribuição relativa dos 12 caracteres agronômicos, para a diversidade genética (IAC, Campinas-SP, 2006).

\begin{tabular}{cl}
\hline Grupos & \multicolumn{1}{c}{ Genótipos } \\
\hline 1 & Catissol, Embrapa122, BRSG03, IAC-Iarama, BRSG08, BRSG09, BRSG10, BRSG11 \\
2 & M734, VDH487, V20038, V20044, ACA861, Exp1447 \\
3 & Agrobel960 \\
\hline
\end{tabular}

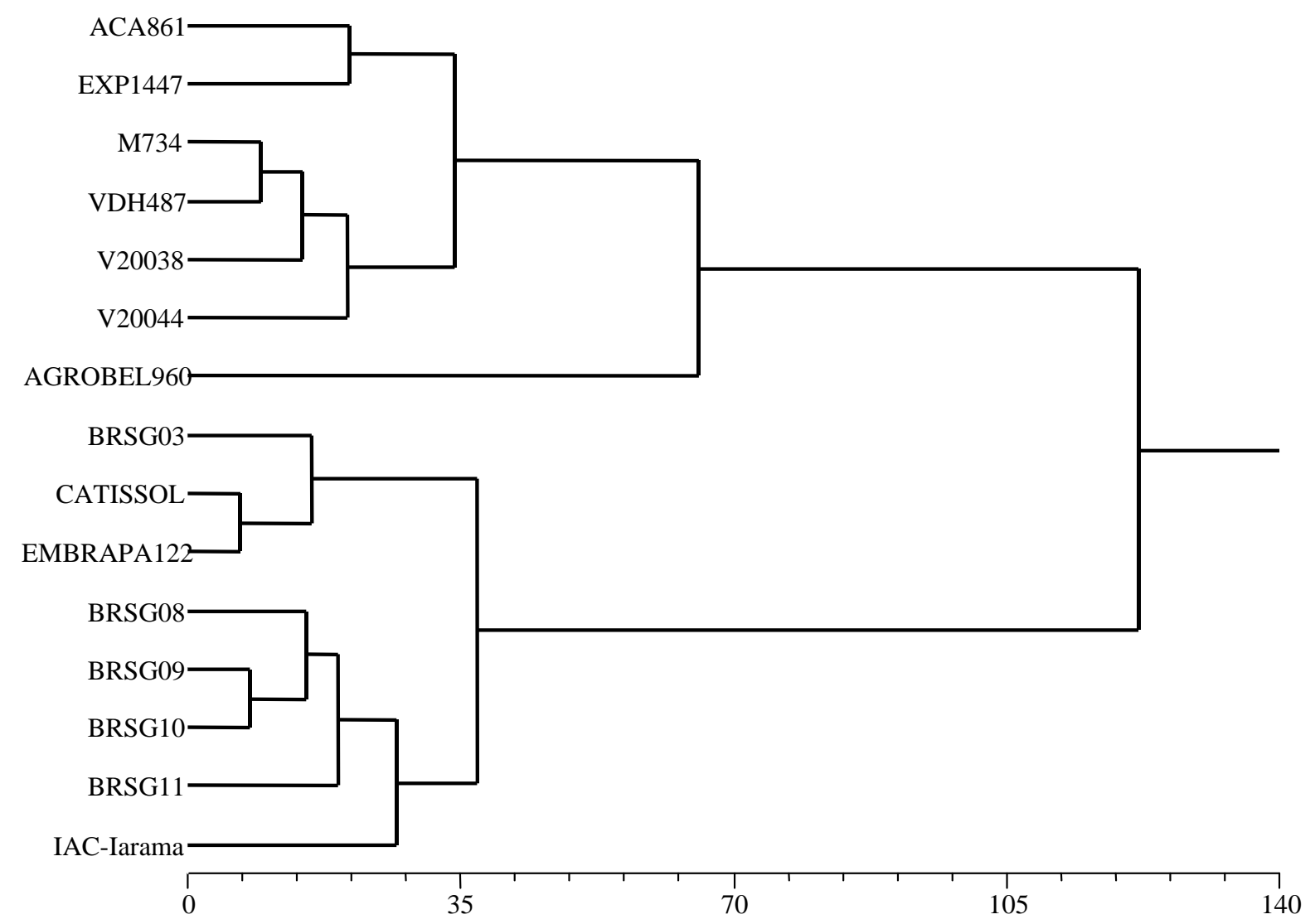

Figura 1 - Dendrograma obtido a partir de 12 caracteres agronômicos, avaliados em 15 genótipos de girassol, com base na distância de Mahalanobis (IAC, Campinas-SP, 2006).

importantes na discriminação da divergência genética entre populações de girassol.

Por meio da razão entre o $\mathrm{CV}_{\mathrm{g}}$ e $\mathrm{CV}_{\mathrm{e}}$ maior que a unidade, infere-se pela facilidade na seleção para os caracteres F, IF, AC e NF. Além disso, as suas altas herdabilidades também contribuem para a seleção. A importância das outras características foi comparativamente menor.

Pelos resultados é possível identificar genótipos com características agronômicas complementares e 
Tabela 4 - Importância relativa de 12 caracteres agronômicos para estudo da diversidade genética entre 15 genótipos de girassol, segundo critério de Singh (1981) e parâmetros associados a essas características (IAC, Campinas-SP, 2006).

\begin{tabular}{crrcrc}
\hline Características & \multicolumn{1}{c}{$S . j$} & $S . j(\%)$ & Herdabilidade & $C V_{g}$ & $C V_{g} / C V_{e}$ \\
\hline IF & $1.225,00$ & 13,30 & 94,00 & 10,64 & 1,97 \\
F & $3.415,69$ & 37,10 & 97,26 & 8,12 & 2,97 \\
NF & 835,77 & 9,10 & 89,06 & 8,68 & 1,42 \\
AP & 395,51 & 4,30 & 87,90 & 8,91 & 1,34 \\
AC & $1.707,88$ & 18,55 & 90,51 & 10,53 & 1,54 \\
DH & 289,71 & 3,15 & 85,50 & 10,15 & 1,21 \\
DC & 192,87 & 2,10 & 58,91 & 4,59 & 0,60 \\
FC & 488,03 & 5,30 & 82,15 & 13,41 & 1,07 \\
GN & 165,60 & 1,80 & 78,26 & 8,38 & 0,95 \\
PG & 202,79 & 2,20 & 62,34 & 9,76 & 0,64 \\
PH & 246,06 & 2,67 & 73,44 & 12,23 & 0,84 \\
RGP & 41,95 & 0,43 & 49,77 & 12,86 & 0,50 \\
\hline
\end{tabular}

S.j: contribuição da variável $x$ para o valor da distância de Mahalanobis entre os genótipos $i$ e $i$ ', $\mathrm{CV}_{\mathrm{g}}$ : coeficiente de variação genética, $\mathrm{CV}_{\mathrm{e}}$ : coeficiente de variação ambiental, IF: início do florescimento (dias), F: 50\% do florescimento (dias), NF: número de folhas, AP: altura de planta $(\mathrm{cm})$, AC: altura da inserção do capítulo $(\mathrm{cm}), \mathrm{DH}$ : diâmetro da haste $(\mathrm{mm})$, DC: diâmetro do capítulo (cm), CC: curvatura do capítulo, GN: porcentagem de grãos normais, PG: peso de 1000 grãos (g), PH: peso hectolítrico (kg 100L $\left.\mathrm{L}^{-1}\right)$, RGP: rendimento de grãos por planta $\left(\mathrm{g} \mathrm{planta}^{-1}\right)$.

divergentes que poderiam ser utilizados em esquemas de hibridação e/ou seleção com o objetivo de incorporar as características favoráveis de cada parental em uma mesma população ou mesmo obter novas linhagens, a partir desses genótipos, disponibilizando nova variabilidade aos programas de melhoramento genético da cultura (Tabela 2). De acordo com Amorim \& Souza (2005), a extração de linhagens a partir de variedades melhoradas e/ou híbridos simples comerciais é uma alternativa viável, pois esses genótipos foram testados em vários ambientes sendo que, no caso dos híbridos, ainda é possível contar com uma grande proporção de locos favoráveis já fixados.

\section{CONCLUSÕES}

1. Existe variabilidade genética entre os 15 genótipos de girassol para as doze características agronômicas avaliadas.

2. Os caracteres início do florescimento, $50 \%$ florescimento, número de folhas e altura da inserção do capítulo, contribuíram com grande parte da divergência genética observada entre os 15 genótipos de girassol.

3. É possível identificar genótipos divergentes e com características agronômicas complementares, para a extração de linhagens e/ou formação de novas populações.

\section{REFERÊNCIAS BIBLIOGRÁFICAS}

ALVAREZ, M. P.; MANCUSO, N.; FRUTOS, E. Genetic divergence among open pollinated populations of sunflower (Helianthus annuus L.). In: INTERNATIONAL SUNFLOWER CONFERENCE, 14., 1996, Beijing. Proceedings... Beijing: ISA, 1996. p. 230-235.

AMORIM, E. P.; SOUZA, J. C. Híbridos de milho inter e intrapopulacionais obtidos a partir de populações $S_{0}$ de híbridos simples comerciais. Bragantia, Campinas, v. 64, n. 4, p. 561-567, 2005. 
BRASIL. Ministério da Agricultura e Reforma Agrária. Regras para análise de sementes. Brasília, DF: Agiplan, 1992. 365 p.

CARTER, J. F. Sunflower science and technology. Madison: American Society of Agronomy. 1978. 505 p. (Series agronomy, 19).

CASTRO, C.; FARIAS, J. R. B. Ecofisiologia do girassol. In: LEITE, R. M. V. B.; BRIGHENTI, A. M.; CASTRO, C. (Eds.). Girassol no Brasil. Londrina: Embrapa Soja, 2005. p. $163-218$.

CONNOR, J. D.; HALL, A. J. Sunflower physiology. In: SCHNEIDER, A. A. (Ed.). Sunflower technology and production. Madison: ASA/CSSA/SSSA, 1997. p. 113-181. (Series of monographs, 35).

CRUZ, C. D. GENES: aplicativo computacional em genética e estatística. Viçosa: UFV, 1997. 442 p.

CRUZ, C. D.; CARNEIRO, P. C. S. Modelos biométricos aplicados ao melhoramento genético. Viçosa: UFV, 2003. $585 \mathrm{p}$.

EMPRESA BRASILEIRA DE PESQUISA AGROPECUÁRIA. Banco de dados climáticos do Brasil. Campinas, 2006. Disponível em: <http:// www.bdclima.cnpm.embrapa.br >. Acesso em: 10 out. 2006

EMPRESA BRASILEIRA DE PESQUISA AGROPECUÁRIA. Informes da avaliação de genótipos de girassol: 1996 e 1997. Londrina, 1997. 116 p. (Documentos, 110).

GOMES, E. M. Parâmetros básicos para a irrigação sistemática do girassol (Helianthus annuus L.). 2005.94 f. Tese (Doutorado em Engenharia) - Universidade Estadual de Campinas, Campinas, 2005.

HASSAN, S. W. Heritability, genetic correlations and predicted gains from $S_{1}$ families in two random mated sunflower populations. 2001. $186 \mathrm{f}$. Thesis (Doctor of Philosophy) - University of the Punjab, Lahore, 2001.

KNOWLES, P. E. Morphology an anatomy. In: CARTER, J. F. (Ed.). Sunflower science and technology. Madison: ASA, 1978. p. 55-88.

MANJULA, K.; NADAF, H. L.; GIRIRAJ, K. Genetic diversity in non-oil seed sunflower (Helianthus annuus
L.) genotypes. Helia, Novi Sad, v. 24, n. 34, p. 17-24, 2001.

MILJANOVIC, T.; BOZA, P.; ATLAGIC, J.; SKORIC, D. Morphological variability of $H$. giganteus L. and $H$. maximiliani Sch. populations. Helia, Novi Sad, v. 23, n. 32, p. 45-52, 2000.

OLIVEIRA, M. F.; CASTIGLIONI, V. B. R.; CARVALHO, C. G. P. Melhoramento do girassol. In: LEITE, R. M. V. B.; BRIGHENTI, A. M.; CASTRO, C. (Eds.). Girassol no Brasil. Londrina: Embrapa Soja, 2005. p. 269-297.

QUAGGIO, J. A.; UNGARO, M. R. G. Girassol. In: RAIJ, B. van; CANTARELLA, H.; QUAGGIO, J. A.; FURLANI, A. M. C. (Eds.). Recomendações de adubação e calagem para o Estado de São Paulo. Campinas: IAC, 1997. p. 198.

RAO, G. M.; REDDY, L.; KULKARNI, R. S.; RAMESH, S.; REDDY, S. S. L. Prediction of heterosis based on genetic diversity of parents through regression analysis in sunflower (Helianthus annuus L.). Helia, Novi Sad, v. 27, n. 41, p. 51-58, 2004.

ROMANO, A. B.; VÁZQUEZ, A. N. Origin of the argentine sunflower varieties. Helia, Novi Sad, v. 26, n. 38, p. $127-$ 136, 2003.

SANKARAPANDIAN, S. V. R.; MUPPIDATHI, R.; RAJARATHINAM, S.; CHIDAMBARAM, S. Genetic divergence in sunflower. Madras Agricultural Journal, Coimbatore, v. 83, n. 10, p. 637-639, 1996.

SCOTT, A. J.; KNOTT, M. A. A cluster analysis method for grouping means in the analysis of variance. Biometrics, Washington, v. 30, n. 3, p. 507-512, 1974.

SINGH, D. The relative importance of characters affecting genetic divergence. The Indian Journal of Genetics and Plant Breeding, New Delhi, v. 41, n. 1, p. 237-245, 1981.

SINGH, D. A.; SINGH, S. M. Impact of irrigation on sunflower productivity. In: INTERNATIONAL SUNFLOWER CONFERENCE, 18., 2000, Toulouse. Proceedings... Toulouse: ISA, 2000. p. 109-114.

SUBRAHMANYAM， S. V.; KUMAR， S. S.; RANGANATHA, A. R. G. Genetic divergence for seed parameters in sunflower (Helianthus annuus L.). Helia, Novi Sad, v. 26, n. 38, p. 73-80, 2003. 
TEKLEWOLD, A.; JAYARAMAIAH, H.; JAGADEESH, B. N. Correlation and path analysis of physio-morphological characters of sunflower (Helianthus annuиs L.) as related to breeding method. Helia, Novi Sad, v. 23, n. 32, p. 105$114,2000$.
UNGARO, M. R. G. Potencial da cultura do girassol como fonte de matéria-prima para o programa nacional de produção e uso de biodiesel. In: CAMARA, G. M.; HEIFFIG, L. S. Agronegócio de plantas oleaginosas: matérias-primas para o biodiesel. Piracicaba: Esalq, 2006. p. 57-80. 